\title{
Avaliação participativa de um programa de prevenção e tratamento de Doenças Crônicas Não Transmissíveis
}

\author{
Participatory evaluation of a noncommunicable chronic disease \\ prevention and treatment program
}

Patricia Asfora Falabella Leme', Gastão Wagner de Sousa Campos'

DOI: 10.1590/0103-1104202012604

RESUMO Trata-se da avaliação de um programa de prevenção e tratamento de Doenças Crônicas Não Transmissíveis (DCNT) oferecido à comunidade de uma universidade pública por ambulatório localizado em suas dependências. O processo avaliativo teve como objetivo apreender a dinâmica e compreender a forma de interação entre os atores envolvidos no cotidiano do programa, partindo do entendimento dos seus grupos de interesse, formados pela equipe, usuários, gestores e profissionais encaminhadores. Realizou-se pesquisa qualitativa de caráter participativo e com dimensão formativa para ampliar a possibilidade de aperfeiçoamento do programa pelos sujeitos envolvidos a partir de elementos oriundos de sua prática. A Avaliação de Quarta Geração de Guba e Lincoln e o Método Paideia de Campos foram norteadores metodológicos da pesquisa. A análise do material empírico foi agrupada em três núcleos temáticos: método de trabalho, equipe e gestão do programa. Constatou-se que uma escuta reflexiva dos profissionais é fator decisivo para ampliar a autonomia dos usuários e sua adesão terapêutica; a realização de grupos educativos no local de trabalho favoreceu a captação para tratamento e participação dos usuários, especialmente os do gênero masculino; e os encontros dos grupos possibilitam diversos ganhos objetivos e subjetivos, como a interação social entre pessoas de diferentes áreas da universidade.

PALAVRAS-CHAVE Avaliação em saúde. Pesquisa sobre serviços de saúde. Planos e programas de saúde. Doenças crônicas. Gestão em saúde.

\begin{abstract}
This work concerns the evaluation of a program for the prevention and treatment of Chronic Non-Communicable Diseases (NCD) offered to the community assisted by a public university by means of its outpatient health facility. The evaluation process sought to apprehend the dynamics and to understand the form of interaction between the actors involved in the daily routine of the Program grounded on the understanding of its interest groups, composed of staff, users, managers and referral professionals. A qualitative, participatory and formative research was conducted to broaden the Program possibilities of improvement by the stakeholders based on elements derived from their experience. Guba' and Lincoln' Fourth Generation Evaluation and Paideia' Method of Campos guided the research methodology. The empirical material analysis was grouped into three thematic clusters: working method, team, and program management. It was revealed that a reflective listening by professionals is a deciding factor to extend the autonomy of users and their therapeutic adherence; that the gathering of educational groups in the work premises favored the participation of users and their capture for treatment, especially as for males; and that the group meetings allow for various objective and subjective gains, such as social interaction among people from different areas of the University.
\end{abstract}

1 Universidade Estadual de Campinas (Unicamp) Campinas (SP), Brasil. patricia@cecom.unicamp.br
KEYWORDS Health evaluation. Health services research. Health programs and plans. Chronic disease. Health management. 


\section{Introdução}

Este artigo trata da avaliação de um programa de prevenção e tratamento de Doenças Crônicas Não Transmissíveis (DCNT) ofertado por ambulatório que atende à comunidade interna de uma universidade pública da cidade de Campinas, São Paulo, com população estimada em 50 mil pessoas.

A ideia do programa, implantado em 2013, surgiu após a identificação de um perfil preocupante em um dos órgãos da universidade: a maioria com níveis de Pressão Arterial (PA) limítrofes ou elevados, sobrepeso ou obesidade, hábitos alimentares inadequados e sedentarismo; grupo formado principalmente por funcionários não docentes do sexo masculino, entre 45 e 64 anos de idade, com menor faixa salarial e baixa escolaridade.

O programa foi pioneiro em sua instituição por utilizar intervenção coletiva com equipe multidisciplinar embasada nas publicações 'Como trabalhamos com grupos'1 e "Entrevista motivacional no cuidado à saúde'2. A Entrevista Motivacional foi utilizada originalmente para auxiliar alcoolistas e posteriormente adaptada para diferentes contextos da área da saúde ${ }^{3}$. Os profissionais receberam recomendações para adotar postura de orientadores e evocar motivação para a mudança sem impor soluções, evitando julgamentos e respeitando a autonomia e a liberdade de escolha do usuário.

Existem duas vertentes do Programa: uma denominada Motivacional, voltada para toda a comunidade no campo da promoção de saúde, e outra que faz seguimento de portadores de Hipertensão Arterial Sistêmica (HAS), denominada Terapêutico. A equipe de profissionais é formada por clínicos, dentistas, educador físico, enfermeiros, fisioterapeutas, psicólogas, psiquiatras e assistente social.

A vertente Motivacional possui dois objetivos: provocar mudanças benéficas por meio de reflexão coletiva sobre conceito de saúde, autocuidado, corresponsabilização, cultura do excesso, poder de escolha versus vitimização, estilo de vida para se ter saúde, que inclui alimentação saudável, prática de atividade física, abandono de vícios etc., entre outros temas; e, por meio da aferição de PA, glicosimetria e Índice de Massa Corpórea (IMC), encaminhar os usuários com resultados alterados para outras formas de cuidado, como o Terapêutico. Realizam-se encontros com duração de 90 minutos, em grupos com cerca de doze usuários e três profissionais, orientados a operar com diretrizes gerais da saúde coletiva se posicionando para além do seu núcleo. A distinção entre campo e núcleo de saberes e práticas foi definida anteriormente por Campos 4 .

Para favorecer a adesão dos servidores, ocorre uma fase prévia de sensibilização das chefias e indica-se um facilitador local para organizar os encontros, que acontecem no próprio local de trabalho, em horário laboral. Até 29/08/2018, 1.011 usuários de 17 setores da universidade já haviam participado dos encontros. O perfil desses usuários é de aproximadamente $53 \%$ do gênero masculino e $79 \%$ na faixa entre 30 e 59 anos, sendo cerca de $30 \%$ encaminhados para a outra vertente do programa, dita Terapêutico.

O Terapêutico objetiva motivar o autocuidado e a adesão ao tratamento da HAS, doença que vem apresentando prevalência crescente: verificou-se entre munícipes de São Paulo, de 2003 a 2015, um aumento de $27 \%$ na faixa de 20 a 59 anos e de $19 \%$ a partir de 60 anos $^{5}$. O Ministério da Saúde prioriza esse agravo e recomenda seu manejo adequado, gestão da linha do cuidado, vinculação e responsabilização com equipes e produção da autonomia do usuário ${ }^{6}$. Nesse caminho, o Terapêutico cria um espaço de diálogo e troca de vivências e experiências, de forma a contribuir com o fortalecimento dos sujeitos para que se reconheçam capazes de provocar mudanças em suas vidas e resgatar poderes muitas vezes perdidos no contexto do adoecimento.

Além do cuidado individual, os usuários 
participam, a cada quatro meses, de encontros grupais de uma hora com 15 pessoas. Os profissionais ofertam informações tanto no campo da promoção à saúde como em seus núcleos, como especialistas. Aferição de PA e cálculo de IMC seguem-se por fala aberta dos participantes, com estímulo ao compartilhamento de experiências e espaço para questões subjetivas. Logo após esse momento, usuários com demandas identificadas previamente nos prontuários ou durante os grupos passam em consulta com médico ou enfermeiro.

No momento da pesquisa, cerca de 600 usuários hipertensos estavam cadastrados no Terapêutico. O perfil de 2018 revelou $51 \%$ do sexo masculino, $6 \%$ na faixa etária dos 20 aos 40 anos, $18 \%$ dos 41 aos 50 anos, $34 \%$ dos 51 aos 60 anos e $42 \%$ acima de 60 anos.

Para elaborar o programa em questão, em termos de seu conteúdo e formato, aprendizado sobre Entrevista Motivacional, e discussão sobre dinâmicas de grupo, foi criado um espaço coletivo de gestão com profissionais e gestores de diversas áreas; tal espaço foi mantido e, atualmente, é utilizado para discutir questões operacionais, construção de projetos terapêuticos singulares e contratar mudanças para melhor alcance dos objetivos. Definem-se como espaços coletivos:

[...] Arranjos ou dispositivos (settings) que propiciem a interação inter sujeitos. Mais ainda, espaços em que a análise de situações e a tomada de decisão seja possível. Instituir o hábito de avaliar os processos e tarefas, redefinindo-os conforme o acordado ${ }^{7}$.

Após alguns anos de implantação dessa oferta de saúde, nasceu em seus profissionais e gestores a vontade de compreendê-la melhor por meio de uma avaliação, que viria a ser a primeira avaliação sistemática de ação ou programa nessa unidade de saúde, e, por seu intermédio, gerar novos espaços coletivos de reflexão agregando usuários, possibilitando-se análises e intervenções mais qualificadas para trazer melhorias.

\section{Metodologia}

A pesquisa ocorreu em um centro de saúde universitário e o objeto da avaliação foi seu programa de prevenção e tratamento de DCNT. A escolha do método, pactuada em reunião do Colegiado Gestor do Órgão, partiu da premissa de envolvimento participativo de usuários, profissionais e gestores. Assim, muito além de ser instrumento de gestão do programa, se agregaria ao ato de avaliar uma oportunidade de trazer reflexões transformadoras de pessoas.

Assim, tomando-se como bases metodológicas a Avaliação de Quarta Geração de Guba \& Lincoln 8 e o Método Paideia de Campos ${ }^{4}$, realizou-se pesquisa qualitativa formativa centrada em grupos de interesse, adotando-se perspectiva construtivista, responsiva e com abordagem hermenêutico-dialética para análise do corpo de informações recolhidas.

A Avaliação de Quarta Geração baseia-se em 'negociação e construção' entre organizações, grupos ou indivíduos, denominados stakeholders, ou grupos de interesse. Propõe-se ouvir usuários, familiares, trabalhadores e coordenadores para a avaliação de serviços e programas de saúde-11, desvelando-se aspectos das relações que constituem seu cotidiano, além de números e aspectos do que é ofertado. Já o Método Paideia ou Método da Roda, é uma proposta de reforma democrática das instituições que cria arranjos de cogestão de coletivos organizados para realizar alguma tarefa ou objetivo - com negociação, mediação de conflitos, composição articulada de projetos e planos entre usuários, trabalhadores e governantes. Reconhece uma tríplice finalidade das instituições e organizações de saúde: produzir valores de uso; permitir e estimular os trabalhadores a ampliarem sua capacidade de reflexão, de cogestão e, em decorrência, sua realização profissional e pessoal; e garantir a própria sustentabilidade e reprodução da instituição. O método possui três eixos de aplicação: apoio institucional, apoio matricial e clínica ampliada e compartilhada4,12. 
Furtado"1 observou a existência de alinhamento entre Método Paideia e Avaliação de Quarta Geração: ambos possuem referencial participativo e construtivista e uma lógica da regulação democrática, oferecem espaços grupais de discussão e têm objetivos ligados à capacitação e desenvolvimento de coletivos implicados em programas ou serviços.

Esta pesquisa cumpriu as seguintes etapas da Avaliação de Quarta Geração:

1) Formalização do contrato e identificação dos grupos de interesse - a proposta foi validada pelo colegiado gestor da instituição e pela equipe de profissionais do programa, que elegeram quatro grupos de interesse:

a) Equipe: profissionais que atuavam no programa;

b) Usuários: selecionados por amostra intencional sob o critério de boas condições de comunicação e, para os do Terapêutico, também ter participado de pelo menos três encontros, ou frequentar o grupo há pelo menos um ano;

c) Gestores: profissionais hierarquicamente superiores aos membros da equipe ou do grupo gestor de promoção à saúde e prevenção de doenças da instituição; e

d) Profissionais encaminhadores: foram convidados por amostra intencional profissionais da assistência que poderiam encaminhar os usuários para o programa e não participavam diretamente dele.

A inclusão deste último grupo foi feita por sugestão da equipe; o surgimento de novos grupos de interesse durante a avaliação é considerado provável por Guba \& Lincoln: "Aliás, é dever do avaliador fazer todo o possível para revelar outros públicos"8.

2) Coleta de dados - análise de documentação referente ao programa, observação livre e não participante e oficinas com cada grupo de interesse. As impressões colhidas foram registradas em diário de campo.
Conduziram-se seis 'Oficinas de avaliação e proposições' sob critérios de saturação da amostragem $^{13}$ : duas para o grupo equipe, duas para os usuários, uma para o grupo gestores e uma para os profissionais encaminhadores, com cerca de duas horas cada. Três questões iniciais orientadoras foram demandadas: $\mathrm{O}$ que você aprecia no programa?, O que não aprecia? e Você daria alguma sugestão para trazer melhorias ao programa?. Depois, realizaram-se círculos hermenêutico-dialéticos, que, ao final, resultaram em construções conjuntas de cada grupo de interesse a partir das falas originais dos participantes individuais. As oficinas foram gravadas e transcritas.

As respostas e os comentários coletados foram organizados em três Unidades de Análise Temáticas: Pontos Positivos, Pontos Negativos e Sugestões de Melhoria. Em seguida, utilizaram-se categorias de análise não apriorística para abrir a possibilidade de interpretação do material produzido. Essas categorias foram denominadas Unidades de Informação: Método, Profissionais e Gestão. Dessa forma, foram produzidos quadros que sistematizaram o conjunto de informações de cada grupo de interesse.

Por fim, conduziu-se uma 'Oficina de negociação e validação' com dois representantes de cada grupo de interesse selecionados por disponibilidade de data - à exceção do grupo de usuários, com apenas um - totalizando-se nove. Nessa etapa, foram realizados círculos hermenêutico-dialéticos em que os textos e narrativas elaborados pela pesquisadora foram devolvidos aos grupos para que fossem emendados ou validados, elaborando-se uma nova e única construção contendo ações separadas por ordem de prioridade para execução futura.

3) Análise - foi cumprida pela constituição do corpus, i.e, compilação de documentos referentes ao Programa, transcrição e resumo de cada oficina, síntese dos dados coletados na observação e na organização dos relatos provenientes do diário de campo, por leitura flutuante, identificação das Unidades Temáticas e das Unidades de Informação e leitura transversal e interpretação, utilizando-se a triangulação de métodos ${ }^{\mathbf{1 4}}$. 
O projeto foi enviado para o Comitê de Ética e Pesquisa (CEP), Certificado de Apresentação para Apreciação Ética (CAAE) 83156217.6.0000.5404, e aprovado por meio de parecer consubstanciado de número 2.544.906. Realizou-se uma análise de implicação $0^{15} \mathrm{da}$ pesquisadora, gestora na instituição em questão.

\section{Resultados e análise}

Houve 52 participantes distribuídos em quatro grupos de interesse (quadro 1). O grupo de usuários, com maioria do sexo masculino, coincide com o perfil do programa, mas não com dados da literatura; Couto e cols. ${ }^{16}$ relataram que tais indivíduos participam menos de atividades educativas de grupo e consultas de enfermagem na atenção primária:

[...] verificamos pouca presença masculina nos grupos educativos ... A caracterização da presença dos homens nos serviços indica que estes costumam priorizar o aspecto curativo, a restauração da integridade corporal e sua funcionalidade adequada.

Quadro 1. Caracterização da amostra

\begin{tabular}{|c|c|c|c|c|}
\hline Grupo de interesse & № & Média de idade (anos) & Gênero & Características \\
\hline Equipe & 14 & 44 & $\begin{array}{l}F=11 \\
M=3\end{array}$ & $\begin{array}{l}4 \text { enfermeiros } \\
2 \text { médicos clínicos } \\
2 \text { psicólogas } \\
2 \text { nutricionistas } \\
2 \text { fisioterapeutas } \\
1 \text { educador físico } \\
1 \text { assistente social } \\
\text { - Participação média de } 3 \text { anos no programa }\end{array}$ \\
\hline Usuários & 21 & 52 & $\begin{array}{l}M=11 \\
F=10\end{array}$ & $\begin{array}{l}\text { Grupo Motivacional = } 3 \\
\text { Grupo Terapêutico = } 20 \\
\text { - Participação média de } 8 \text { encontros, maioria } \\
\text { de funcionários Paepe }\end{array}$ \\
\hline Gestores & 10 & 47 & $\begin{array}{l}F=6 \\
M=4\end{array}$ & $\begin{array}{l}2 \text { dentistas } \\
2 \text { médicos clínicos } \\
2 \text { enfermeiros } \\
2 \text { profissionais administrativos } \\
1 \text { médico psiquiatra }\end{array}$ \\
\hline $\begin{array}{l}\text { Profissionais } \\
\text { encaminhadores }\end{array}$ & 07 & 45 & $\begin{array}{l}M=4 \\
F=3\end{array}$ & $\begin{array}{l}3 \text { enfermeiros } \\
2 \text { médicos clínicos } \\
1 \text { técnica de enfermagem } \\
1 \text { dentista }\end{array}$ \\
\hline Total & 52 & & & \\
\hline
\end{tabular}

Estes autores também observaram maior presença de homens em serviços que disponibilizavam atendimento nas 24 horas, aos sábados ou à noite, assim como no horário de almoço; portanto, sendo quase toda a amostra de usuários composta por servidores, acredita-se que a oferta do objeto avaliado no local e durante a jornada de trabalho tenha influenciado na maior adesão do público masculino ao programa. 
A comunidade universitária é composta por docentes, técnicos e estudantes, e a presença de apenas um aluno pode relacionar-se à faixa etária mais jovem dessa categoria, com menor prevalência de HAS, além da dificuldade de horários pelas disciplinas cursadas. Ainda, a média de idade de 52 anos desse grupo de interesse segue o aumento da prevalência de HAS ao longo da vida 17; já o baixo número de pessoas muito idosas explica-se por sua opção frequente por transferir seu cuidado para a Unidade Básica de Saúde após a aposentadoria.

\section{Construção de significados}

Na fase de observação do 'Motivacional', captaram-se alguns significados construídos pelos usuários sobre o que é ter saúde, estratégias e dificuldades no autocuidado (quadro 2);

Quadro 2. Significados construídos pelos usuários do Motivacional

\begin{tabular}{|c|c|}
\hline O que é ter saúde & Falas \\
\hline $\begin{array}{l}\text { 1- Ser independente } \\
2 \text { - Um bem valioso e insubstituível } \\
\text { 3- Bem-estar }\end{array}$ & $\begin{array}{l}1 \text { - "É tudo, se a gente não tiver não faz nada, depende dos outros" } \\
2 \text { - "Dinheiro a gente constrói com o trabalho, mas se perder a saúde não tem volta" } \\
3 \text { - "Sentir-se bem" }\end{array}$ \\
\hline Estratégias de autocuidado & Falas \\
\hline $\begin{array}{l}1 \text { - Adotar um estilo de vida saudável } \\
2 \text { - Cuidar da saúde emocional } \\
3 \text { - Fazer exames regularmente }\end{array}$ & $\begin{array}{l}1 \text { - "Comer bem e fazer exercícios", "Tomar bastante água", "Dormir bem", "Não } \\
\text { exagerar nos alimentos" } \\
2 \text { - "Saber ser feliz, ter o coração saudável... Equilíbrio emocional!" } \\
3 \text { - "Todo ano faço check up: avalio pressão, diabete, triglicérides, faço exame de } \\
\text { toque retal" }\end{array}$ \\
\hline Dificuldades no autocuidado & Falas \\
\hline $\begin{array}{l}1 \text { - Dupla jornada, sobrecarga, falta de } \\
\text { tempo } \\
2 \text { - Interpretar a mudança de hábito } \\
\text { como compulsória } \\
3 \text { - Demora no alcance dos resultados }\end{array}$ & $\begin{array}{l}1 \text { - "Tenho tido dificuldades com o tempo. Filhos, } \\
\text { marido, trabalho... estou sobrecarregada. Mas eu sei que preciso" } \\
2 \text { - "Quando a gente acha que é obrigação, depois de algum tempo, a gente quer se } \\
\text { libertar, considera uma 'privação"' } \\
3 \text { - "Tudo hoje é muito rápido, a comunicação, com a internet. Daí, quando a gente } \\
\text { não consegue rápido o resultado que quer, a gente abandona... A gente não tem } \\
\text { noção de que tem que ser contínuo e não pontual. Não tenho que fazer exercício } \\
\text { para perder peso, mas pela saúde". }\end{array}$ \\
\hline
\end{tabular}

Fonte: Elaboração própria.

Da mesma forma, a observação do Terapêutico trouxe à tona significados com relação às estratégias de autocuidado no controle da PA e às dificuldades com esse objetivo (quadro 3). 
Quadro 3. Significados construídos pelos usuários do Terapêutico

\begin{tabular}{ll}
\hline $\begin{array}{l}\text { Estratégias de autocuidado para } \\
\text { controle da pressão arterial }\end{array}$ & Falas \\
\hline - Tomar as medicações prescritas & - "Tomo todo dia às 5 h00 e às 17h00" \\
- Fazer atividade física & - "Todo dia eu ando de bicicleta" \\
- Restringir a alimentação & - "Faço natação e controlo a alimentação" \\
- Medir a PA no Centro de Saúde da & - "De duas a três vezes por semana. Aqui no grupo, me falaram para medir pelo menos \\
Comunidade (Cecom) e em casa & uma vez por semana; mas quando estou muito suado, de noite, também meço" \\
& - "Recomendo para todo mundo a paz de espírito. Estou de bem com a vida" \\
\hline Dificuldades no autocuidado & Falas \\
\hline - Esquecer de tomar a medicação & - "Já me esqueci de tomar durante três dias. Aliás, agora tenho uma caixinha onde \\
- Muitos encontros sociais & coloco os remédios por dia, para eu me lembrar se já tomei ou não" \\
- Gostar de refrigerante & - "Muita festa, muita comida, Natal, Ano Novo..." \\
& - "Meus filhos é que dão bronca em mim, eu é que tomo refrigerante" \\
\hline
\end{tabular}

Fonte: Elaboração própria.

\section{Unidades de Análise Temática e Unidades de Informação}

As 'Oficinas de avaliação e proposições' originaram as Unidades de Análise Temática
'Pontos positivos e pontos negativos, ou desafios, e sugestões', desdobradas nas Unidades de Informação: Método, Profissionais e Gestão, tanto para o Motivacional (quadro 4) como para o Terapêutico (quadro 5).

Quadro 4. Unidades de Análise Temáticas do Programa Motivacional

\section{Pontos positivos}

\section{A) método}

- modelo de 'fala aberta' e escuta qualificada

- cuidado multidisciplinar

- espaço para reflexão profissional após cada encontro

- captação e oferta para continuidade de cuidado dos usuários com elevação de pressão arterial, glicemia capilar ou imc

B) profissionais

- clareza em seu papel e nos objetivos do programa

- busca constante de aperfeiçoamento na escuta

- aprendizado e aceitação com relação ao trabalho em grupos e em equipe

- transferência da expertise dos grupos para os atendimentos individuais

- melhoria na relação de poder com os usuários

- participação ativa nas melhorias do programa

- apropriação na construção do programa e expressão de satisfação em executá-lo

C) gestão

- 'apoio institucional' ao programa desde a sua idealização

- espaço coletivo mensal com reflexões que resultam em melhorias para o programa

- presença essencial de uma gestão administrativa do programa

- apoio dos gestores das áreas assistenciais na valorização desse novo modelo de ação em saúde

\section{Desafios e sugestões}

a) método

- ainda é preciso melhorar a escuta profissional e a forma de conduzir os grupos

- alguns participantes dos encontros com medidas alteradas não são encaminhados para seguimento no ambulatório, por não serem parte da sua clientela, como, por ex., funcionários terceirizados da limpeza 


\section{Quadro 4. (cont.)}

\section{Desafios e sugestões}

B) profissionais

- reforçar um olhar mais sensível às singularidades, desejos e possibilidades dos usuários, evitando-se a culpabilização

e auxiliando a construção da sua autonomia para a promoção da saúde

C) gestão

- criar um espaço ou instrumento oficial de feedback dos usuários que permitam melhor avaliação dos resultados e a

construção de novas melhorias para o programa

- melhorar a divulgação interna, ao cecom e à universidade, e externa do programa

- ofertar ações de treinamento para os profissionais

- garantir equipe mínima de profissionais necessária ao alcance dos objetivos do programa

Fonte: Elaboração própria.

Quadro 5. Unidades de Análise Temáticas do Programa Terapêutico

\section{Pontos positivos}

A) método

- modelo de 'fala aberta' e escuta qualificada

- cuidado multidisciplinar

- favorece vínculo à equipe do programa

- monitoramento do peso e da pa como fator motivacional

- oportunidade de consulta médica ou de enfermagem após os encontros

- contato qualificado feito pela assistente social com os usuários faltosos

B) profissionais

- clareza em seu papel e nos objetivos do programa

- busca constante de aperfeiçoamento na escuta

- aprendizado e aceitação com relação ao trabalho em grupos e em equipe

- transferência da expertise dos grupos para os atendimentos individuais

- participação ativa nas melhorias do programa

- vínculo estreito com os usuários

- melhoria na relação de poder com os usuários

- empenho na solução das demandas dos usuários pela articulação com as demais ofertas do serviço

C) gestão

- 'apoio institucional' ao programa desde a sua idealização

- eficácia do programa: resultados objetivos e subjetivos

- espaço coletivo mensal com reflexões que resultam em melhorias para o programa

- presença essencial de uma gestão administrativa do programa

- apoio dos gestores das áreas assistenciais na valorização desse novo modelo de ação em saúde

\section{Desafios e sugestões}

A) método

- ainda é preciso melhorar a escuta profissional e a forma de conduzir os grupos: falar menos, focar nas conquistas

- diversificar as ofertas nos encontros e utilizar mais recursos audiovisuais

- refletir sobre número e composição multiprofissional ideal dos grupos

- criar um momento de integração entre usuários e profissionais ao final dos primeiros encontros, para início ou fortalecimento do vínculo

- estabelecer um espaço de reflexão dos profissionais ao final de cada encontro

B) profissionais

- reforçar um olhar mais sensível às singularidades, desejos e possibilidades dos usuários, evitando-se a culpabilização e auxiliando na construção da sua autonomia para a promoção da saúde 
Quadro 5. (cont.)

Desafios e sugestões

C) gestão

- estabelecer critérios formais de acesso, seguimento e alta do programa

- criar estratégias para aumentar a captação dos usuários hipertensos

- estratificar o risco dos usuários novos com vistas à atenção prioritária dos casos mais severos

- criar estratégias de cuidado prioritárias para hipertensos de alto risco que não aderem a grupos

- utilizar melhor ou criar novos espaços coletivos

- melhorar a articulação do programa 'cuide-se' aos demais programas do cecom

- inserir novas tecnologias ao programa: aplicativos, grupo de whatsapp

- estimular a realização de pesquisas científicas

- melhorar a divulgação interna e externa do programa

- ofertar ações de treinamento para os profissionais

- garantir equipe mínima de profissionais necessária ao alcance dos objetivos do programa

Fonte: Elaboração própria.

Na 'Oficina de negociação e validação', representantes dos grupos de interesse agruparam e priorizaram as sugestões em um plano de ação, a ser executado ao término da avaliação.

\section{Reflexão}

Considerando-se a frequência com que aparecem nas falas dos diversos grupos de interesse e relevância no contexto avaliatório, foram destacados alguns temas para discussão.

\section{O PAPEL DA ESCUTA}

O modelo de escuta qualificada e compartilhamento de experiências entre os usuários do Programa ora avaliado é, per se, instrumento que pode favorecer a ampliação do objeto de trabalho e a procura por resultados eficientes, além de auxiliar o desenvolvimento de habilidades pessoais e a produção crescente de autonomia no processo de cuidar da própria saúde, recomendação da Nova Promoção da Saúdee.

Eu participo do grupo há um bom tempo, é uma experiência que tá dando certo, e realmente os usuários gostam de participar, tem uma expressão livre 'né'? Ficam muito à vontade, trazem suas dúvidas. A fala aberta eu acho que é um dos pontos positivos mesmo. (Nutricionista).
Na prática clínica tradicional, a escuta objetiva auxiliar a formulação de diagnósticos, aprendendo inclusive o que deve ser ouvido e o que deve ser ignorado. Segundo Ramos Jr. ${ }^{19}$, citado por Bedrikow e Campos 20(610):

[...] a anamnese deve ser feita correspondendo à informação e à composição dos sintomas, de tal forma que seja possível o raciocínio para os diagnósticos obrigatórios, anatômicos, funcionais e etiológicos. Deverão ser expurgadas todas as informações ou expressões que nenhuma relação apresenta com a fisiopatologia do órgão em questão.

Outro tipo de escuta, centrada na relação clínica junto à fala do usuário, foi proposta por Freud no início do século 20, segundo Onocko Campos e Campos ${ }^{21}$; e Balint ${ }^{20}$, citado por Bedrikow e Campos 20(612), sugeriu "entrevista prolongada, com base na habilidade da escuta por parte do médico". Tal escuta é ferramenta essencial da Clínica Ampliada ou Clínica do Sujeito, em que, além da enfermidade, segundo Campos ${ }^{7(57)}$, "pretende-se também incluir o Sujeito e seu Contexto como objeto de estudo e de práticas da Clínica”. Nessa linha, Cunha entende que sujeitos com hipertensões arteriais semelhantes, mas contextos diferentes podem apresentar 
consequências e gravidades distintas, e que o grande benefício seria produzir um projeto terapêutico considerando-se essas distinções singulares, como, por exemplo, estar ou não empregado 22 .

A equipe baseia-se neste segundo tipo de escuta, embora ressalte que profissionais ainda intervêm desnecessariamente durante os encontros, sugerindo mudanças de hábito baseadas em suas próprias vivências e realidade. Isso pode ocorrer em razão de sua pouca expertise no instrumento. Diante disso, foi sugerida uma ação educadora sobre 'como conduzir a escuta'.

\section{PROMOC̣ÃO DA SAÚDE}

O Motivacional, inicialmente, direcionava-se à prevenção de HAS, Diabetes Melito (DM) e obesidade, seguindo o modelo de Leavell \& Clark $^{23}$ de foco na doença. Reflexão da equipe em seu espaço coletivo concluiu que os participantes, muitos sem doenças crônicas diagnosticadas, se beneficiariam mais de abordagem focada no cuidado à saúde. Assim, atualmente o modelo afina-se aos objetivos propostos na Carta de Ottawa ${ }^{24}$, atuando para capacitar os usuários tanto na identificação como no controle dos fatores determinantes da sua saúde, por meio de mudanças no modo e nas condições de vida.

Todavia, parece assemelhar-se à ação de empowerment psicológico de Carvalho ${ }^{25}$, restrita à esfera microindividual e superlativando o potencial de influência dos usuários sobre a própria saúde - ainda que importante -, desconsiderando o contexto sociopolítico em que estão inseridos. Assim, recomenda-se incluir uma reflexão sobre qualidade de vida no trabalho e seus determinantes, ampliando-se a dimensão do programa para uma ação de empowerment comunitário, objetivando uma transformação do status quo.

Outra sugestão é articular conceitos de promoção da saúde e redução de danos na proposição de estratégias aos usuários de contextos singulares difíceis, evitando-se neles o sentimento de culpa e uma vida presa a "mecanismos disciplinares e higienistas"26.

Às vezes, a gente pensa no ideal... a gente quer o bem deles, não é? Ontem, uma mulher falou: Eu tenho duas filhas, e não dá pra fazer exercício físico... Daí a gente pergunta: o que você enxerga que é possível fazer? Duas vezes por semana... Vai ser o suficiente pra diminuir a pressão dela? Talvez não, mas naquele momento é aquilo que ela consegue. (Profissional).

\section{INTERDISCIPLINARIDADE}

O cuidado multiprofissional foi outro destaque positivo do Programa capaz de mudar o paradigma da Instituição com relação aos atendimentos em grupo e ao sentido do trabalho em equipe:

É natural que na Saúde as pessoas formadas com foco principal na atenção individual desconfiem bastante da atenção coletiva, não valorizem o suficiente... e eu percebo que isso foi bastante superado. (Gestora).

Os resultados da pesquisa permitem classificar a equipe do programa como 'interdisciplinar' e 'equipe integração'. Segundo Almeida Filho ${ }^{27}$, interdisciplinaridade exige identificação de uma problemática comum e plataforma de trabalho conjunto, em que se produz "um discurso capaz de atravessar as fronteiras disciplinares", e, segundo Peduzzi ${ }^{28}$, na 'equipe integração' ocorreria uma contemplação da multidimensionalidade do objeto de trabalho de cada área profissional. A equipe relatou, em várias ocasiões, ganhos na troca de conhecimentos, colaboração e integração:

Antes de participar do programa 'eu via uma Hipertensão', e já encaminhava pro médico... Hoje em dia já dou aula, praticamente... Diminuí a minha angústia, melhorou a qualidade da consulta, a pessoa sai muito mais agradecida, muitas vezes até do Pronto Atendimento ... (Enfermeira). 


\section{RASTREAMENTO}

É inequívoco o impacto da redução da PA na morbidade e mortalidade prematura ${ }^{29}$; porém a HAS, frequentemente assintomática nos estágios iniciais, não é sequer diagnosticada, tanto que, no Brasil, essas taxas variam entre $22 \%$ e $77 \%^{30}$. Assim, a identificação pelo Motivacional de indivíduos com PA elevada para tratamento e controle efetivo é considerada de extrema relevância, e foi reconhecida:

Lá mediram minha pressão, e estava um pouco acima do normal. Aí me encaminharam pra cá, comecei a fazer acompanhamento... Eu acho que se não tivesse ido lá, teria demorado mais tempo pra descobrir. (Usuária).

\section{APOIO INSTITUCIONAL}

“[...] é uma função gerencial para a cogestão usada nas relações entre serviços e entre gestores e trabalhadores. Pressupõe postura interativa, tanto analítica como operacional"31(50), podendo ampliar a capacidade de intervenção sobre a oferta e auxiliar a realização pessoal e profissional ${ }^{4}$. Oferecida regularmente à equipe do Programa, desde o seu embrião por gestora da própria instituição, foi fundamental na sua criação e na consolidação como modelo pioneiro.

Em 2012 fomos a um órgão da universidade e 85\% dos funcionários tinham PA elevada... a maioria era SUS dependente, e por incrivel que pareça, já eram pacientes daqui muito antigos. Daí resolvemos apostar num trabalho específico, coletivo pra abordar a hipertensão... Então fizemos um modelo experimental com uma equipe multiprofissional convidada, inclusive, pra opinar no modelo. Então é um programa que começou já de forma bem participativa.... (Gestora, apoiadora).

\section{EDUCAC̣̃̃O EM SAÚDE}

Identificou-se que o Terapêutico fez uso inicialmente daquilo que Freire ${ }^{32(78)}$ chamou 'educação bancária' ao "ato de depositar, ou de narrar, ou de transferir, ou de transmitir 'conhecimentos' e valores aos educandos, meros pacientes”. Um usuário explicou:

Porque fica assim, só vocês falam e a gente ouve aquelas coisas, maravilha, desperta bem a gente. Mas a gente fica só sentado, a gente não tem uma atividade... o cérebro da gente não trabalha, só acumula.

Atualmente, objetiva-se a prática oposta de 'educação libertadora, problematizadora', em que os participantes são vistos como reflexivos, críticos e criadores:

Minha alimentação era muito crítica... À noite eu comia 8 paçocas grandes... Hoje aprendi que não é bem por aí o caminho. Eu tenho me ensinado, os colegas também, os profissionais, que comer faz parte da vida, mas também você tem que ser regrado, principalmente na idade que a gente está. (Usuário).

Entretanto, os usuários também valorizam a necessidade de informação: "A gente está vendo bastante fakenews, não é? O que é realmente verdade, sobre os riscos da hipertensão?". Na Oficina de Validação, combinou-se, então, estimular a reflexão autocrítica compartilhada e, simultaneamente, ofertar conhecimento seguro para auxiliar no aprendizado e na ampliação de autonomia pelos usuários.

\section{ADSCRIC̣ÃO E VÍNCULO}

A avaliação constatou adscrição formal dos usuários à sua equipe multiprofissional. Modelo do Programa, sítio do ambulatório dentro da universidade e registro dos encontros em prontuário foram considerados facilitadores de vínculo longitudinal ${ }^{33}$. A oportunidade de consulta logo após os encontros tem servido para solicitação e análise de exames complementares; escuta a demandas particulares; reforço da adesão terapêutica; ou, simplesmente, emissão de receitas. 
Acho legal essa coisa de passar no médico depois do grupo. Um dia minha pressão estava alta, então o médico já avaliou se ia precisar de medicação, entendeu? Vai ganhando tempo! (Usuário).

Seus principais ganhos decorrem de potencial terapêutico, com redução significativa da mortalidade na maior continuidade dos cuidados ${ }^{34}$, somado à possibilidade de se construírem sujeitos autônomos, aprimorar relações interpessoais e gerar um melhor ambiente de cuidado.

O grupo de usuários valorizou o contato com faltosos como estratégia de cuidado que reforça adesão terapêutica:

Eu tinha grupo e no dia faleceu alguém da família e acabei não indo. Aí eu falei: já que eu não fui, nem vou mais! Então me ligaram pra saber o motivo... mostrou realmente que eles estão preocupados com a minha saúde. Ela falou: não, você não pode, você tem que cuidar da sua saúde... e ela já agendou pra mim de novo. (Usuário).

\section{RELAC̣ÕES DE PODER E SEUS EFEITOS}

Segundo Foucault ${ }^{35}$, ao longo dos séculos, uma relação de poder vem sendo consentida entre profissionais de saúde e usuários por meio de uma tecnologia que chamou 'biopoder', intervindo ao mesmo tempo sobre cada um e sobre a população. $\mathrm{O}$ filósofo encontrou nos conhecimentos instrumento e justificativa para o exercício do poder e declarou sua luta contra os privilégios do saber ${ }^{36}$.

Eu acho que a gente muitas vezes faz essa marcação, tanto do doente, hipertenso, quanto do profissional, que detém o conhecimento. E a gente detém o conhecimento a partir da perspectiva da nossa realidade. (Nutricionista).

A equipe preocupa-se enfaticamente em melhorar essa relação, exercitando sua escuta com menos falas e conhecimentos impostos e criando maior oportunidade de posicionamento, reflexão e autocrítica por parte dos usuários; entretanto, simultaneamente, está impelida de transformar o estilo de vida dos usuários. Os resultados, medidos por meio de esfigmomanômetros, balança e exames, lhes têm feito experimentar ora alegria e otimismo ora angústia e sensação de impotência:

Às vezes a gente insiste: Você tem que mudar..., mas a pessoa não quer, não está motivado, está numa fase de negação, por diversos motivos, e a gente se frustra, porque trabalhar com saúde e com doença é uma coisa muito difícil. Não é?

As dificuldades para mudar hábitos nem sempre se relacionam à falta de motivação ou de conhecimento sobre os benefícios da mudança, com destaque para os determinantes sociais da saúde ${ }^{37}$ e para a influência exercida pela desigualdade social. Na Pesquisa Nacional de Saúde de $2013^{38}$, a prevalência de HAS revelou-se maior naqueles com menor escolaridade, que também apresentaram cinco vezes mais limitações dela provenientes. Ademais, conhecer essa doença não tem se associado à atitude de práticas saudáveis, porque, embora entendam como necessário, poucos mostram motivação concreta para adotá-las ${ }^{39}$, provavelmente pela evolução silenciosa e natureza crônica da hipertensão, além da presença de modelos de estilos de vida e de condições sociais que tendem a ser estáveis ${ }^{40}$.

\section{RESULTADOS E GANHOS}

Um resultado almejado nesse Programa é a adesão terapêutica, que sofre influência de características do medicamento, relação de confiança entre usuário e profissional e atitudes do prescritor ${ }^{41}$. Podem ser facilitadores, além do maior tempo dispensado pela equipe, o respeito pelos pacientes e suas crenças, utilizando-se linguagem popular e tentando-se alcançar o seu universo cultural. E a dificultam pela ausência de sintomas, 'uma má compreensão acerca da importância do tratamento ou da gravidade da enfermidade', ou a falta 
de aceitação quanto a ser portador de uma doença crônica estigmatizante:

Quando eu me vi com hipertensão tive uma resistência, e depois o grupo foi me ajudando a aceitar essa condição... O teu psicológico demora pra... Falei: 'Eu não sou hipertensa, eu estou num estado de pressão alta, mas eu não aceito isso...', mas eu acredito que eu possa melhorar e que posso sair do remédio e falar: 'Eu não sou mais hipertensa'. (Usuária).

Profissionais que atendem usuários, mas não participam do Programa, o reconhecem como uma ferramenta valiosa e eficaz na complementaridade do cuidado da HAS:

[...] a gente acaba não tendo tempo na consulta de se aprofundar naquele assunto. No geral, o paciente que adere ao programa, acaba se beneficiando bastante.

E os encontros também se revelaram um lugar de convívio social para os usuários:

Acho que essa conversa com outras pessoas da universidade é essencial pra nós... O encontro, a interação, acho melhor do que vir aqui me preocupar com peso...

Finalmente, um melhor controle da PA parece estar sendo alcançado. Por tratar-se de estudo qualitativo, obteve-se esta validação pelos depoimentos dos stakeholders:

Minha pressão era sempre alta! Então, depois que criaram o grupo, eu procurei ir em todas as 'palestras'. A partir daí eu sinto que a minha pressão está mais controlada... de não ingerir tanto sódio... E também pela prática de atividade física, que tem ajudado bastante também. (Usuário).

Nós fizemos um levantamento, e após a implantação do programa houve uma redução de 40\% nas crises hipertensivas. (Gestora).

$\mathrm{E}$, acima de qualquer resultado concreto e planejado, a fala de uma das profissionais resume de forma brilhante os potenciais ganhos do Programa avaliado:

Tem muito ganho. Não adianta a gente imaginar que é só o controle da pressão. Um vai melhorar a pressão, outro vai emagrecer... e muitos vem pra cá porque estão sozinhos, e que virão ao grupo 15 anos não só pra tratar a pressão, mas pra se relacionar... O grupo é terapêutico mesmo: pelas trocas, por ter toda uma equipe disponível ali, fazendo uma escuta, estimulando, que a maioria deles não sabe nem perguntar, e aí a pergunta do outro ajuda muito ele a refletir... Pensa: nossa, aquele lá é magrinho, vai fazer 80 anos... puxa, aquele homem mexeu comigo... Então o efeito terapêutico do grupo, é antes, durante e depois. E cada um aproveita do seu jeito.

\section{Considerações finais}

O Programa avaliado envolve relevantes campos como promoção da saúde e cuidado aos indivíduos portadores de hipertensão arterial. Avaliar serviços e programas de saúde pode servir apenas como ferramenta para produzir e melhorar índices de desempenho ou, por meio de espaços coletivos, tornar-se um exercício de cogestão, com acréscimo à própria ação, à democracia nas instituições e à construção de pesquisadores, gestores, profissionais e usuários mais reflexivos e autônomos, menos 'egóicos' e restritos, mais empáticos e inclusivos.

Nesse sentido, foi decisiva a escolha de uma avaliação participativa com base na Avaliação de Quarta Geração e no Método da Roda. Desde Donabedian, citado por Vaitsman e Andrade42(601), a inclusão de usuários é considerada fundamental quando se quer avaliar a qualidade dos serviços de saúde: "A partir de então, os usuários não puderam mais ser ignorados".

A boa participação do seu público masculino, atribuída à oferta do Programa no local e horário de trabalho, reforça a importância 
em considerar tais fatores no planejamento das ações de saúde. No Motivacional, rastreamento periódico e abrangente de HAS, DM e obesidade representa linha de cuidado interessante e oportuna, considerando-se seu perfil assintomático e de grave repercussão quando não tratadas.

No Terapêutico, sentimentos incômodos foram externados pela equipe por não perceber, algumas vezes, mudanças objetivas na saúde dos seus usuários; todavia, o modelo de escuta e compartilhamento de experiências e saberes tem se mostrado eficaz na criação de vínculo, com todos os seus benefícios, no aprendizado, e para diversos outros ganhos, 'mais subjetivos', decorrentes da interação social dentro do grupo, como a possibilidade de encontrar em seus pares exemplos para se espelhar e se transformar - o que Freud chamou 'identificação'43. Finalmente, a presença de apoio institucional foi e tem sido alavanca para o programa nos espaços coletivos criados para esse fim.

Espera-se, para esta e para outras instituições de saúde, uma mudança de paradigma no caminho da democratização da gestão. Recomenda-se, portanto, considerar, na escolha do modelo para novas ações e em seu método de avaliação, a participação de todos os grupos de interesse, a fim do alcance mais abrangente de ganhos, além de meros resultados.

\section{Colaboradores}

Leme PAF (0000-0002-0496-0581)* e Campos GWS (0000-0001-5195-0215)* contribuíram igualmente para a elaboração o manuscrito.

\section{Referências}

1. Zimerman DE, Osorio LC, organizadores. Como trabalhamos com grupos. Porto Alegre: Artes Médicas; 1997.

2. Rollnick S, Miller WR, Butler CC. Entrevista motivacional no cuidado da saúde: ajudando pacientes a mudar o comportamento. Porto Alegre: Artmed; 2009.

3. Lundahl B, Burke BL, Tollefson DR, et al. A Meta analysis of Motivational Interviewing: Twenty Five Years of Empirical Studies. Res. Soc. WorkPract. 2010; 20(2):137-160.

4. Campos GWS. Um método para análise e co-gestão de coletivos. São Paulo: Hucitec; 2000.
5. Stopa SR, Cesar CLG, Segri NJ, et al. Prevalência da hipertensão arterial, do diabetes mellitus e da adesão às medidas comportamentais no Município de São Paulo, Brasil, 2003-2015. Cad. Saúde Pública. 2018; 34(10):e00198717.

6. Brasil. Ministério da Saúde. Plano de ações estratégicas para o enfrentamento das Doenças Crônicas Não Transmissíveis (DCNT) no Brasil 2011-2022 [internet]. Brasília, DF: Ministério da Saúde; 2011. [acesso em 2019 jan 10]. Disponível em: portalms.saude. gov.br/vigilancia-em-saude/vigilancia-de-doencas-cronicas-nao-transmissiveis-dcnt/plano-de-acoes-estrategicas-para-o-enfrentamento-das-doencas-cronicas-nao-transmissiveis-dent.
*Orcid (Open Researcher and Contributor ID). 
7. Campos GWS. A clínica do sujeito: por uma clínica reformulada e ampliada. São Paulo: Hucitec; 2013. Cap. 3. Saúde Paidéia. p. 51-82.

8. Guba E, Lincoln Y. Avaliação de quarta geração, Campinas: Unicamp; 2011.

9. Kantorski LP, Wetzel C, Schwartz E, et al. Uma proposta de avaliação quantitativa e qualitativa de serviços de saúde mental: contribuições metodológicas. Saúde debate. 2009; 33(82):273-82.

10. Bosi MLM, Pontes RJS. Notas sobre a segunda avaliação externa do programa de treinamento em epidemiologia aplicada aos serviços do sistema único de saúde do Brasil - EPISUS: potencialidades do enfoque qualitativo-participativo. Saúde Soc. 2009; 18(3):54953.

11. Furtado JP. A Avaliação como dispositivo [tese]. Campinas: Universidade Estadual de Campinas; 2001.282 p.

12. Campos GWS, Figueiredo MD, Pereira Júnior N, et al. A aplicação da metodologia Paideia no apoio institucional, no apoio matricial e na clínica ampliada. Interface (Botucatu). 2014; 18(supl1):983-95.

13. Minayo MCS. Amostragem e Saturação em Pesquisa Qualitativa: Consensos e Controvérsias. Rev. Pesq. Qualit. 2017; 5(7):1-12.

14. Minayo MCS, Assis SG, Souza ER, organizadores. Avaliação por triangulação de métodos: abordagem de programas sociais. Rio de janeiro: Fiocruz; 2005.

15. Lourau R. La clé des champs. Paris: Éditeurs Anthropos; 1997.

16. Couto MT, Pineiro TF, Valença AO, et al. O homem na atenção primária à saúde: discutindo (in)visibilidade a partir da perspectiva de gênero. Interface (Botucatu). 2010 [acesso em 2020 set 22]; 14(33):257270. Disponível em: https://www.scielo.br/scielo. php?pid=S1414-32832010000200003\&script $=$ sci $_{-}$ abstract\&tlng=pt.
17. Andrade SSA, Stopa SR, Brito AS, et al. Prevalência de hipertensão arterial autorreferida na população brasileira: análise da Pesquisa Nacional de Saúde, 2013. Epidemiol. Serv. Saúde. 2015; 24(2):297-304.

18. Carvalho SR. As contradições da promoção à saúde em relação à produção de sujeitos e a mudança social. Ciênc. Saúde Colet. 2004; 9(3):669-678.

19. Ramos Jr J. Semiotécnica da observação clínica: fisiopatologia dos sintomas e sinais. São Paulo: Sarvier; 1986.

20. Bedrikow R, Campos GWS. Clínica: a arte de equilibrar a doença e o sujeito. Rev Assoc Med Bras 2011; 57(6):610-613.

21. Onocko Campos R, Campos GWS. Co-construção de autonomia: o sujeito em questão. In: Campos GWS, Bonfim JRA, Minayo MCS, et al. Tratado de Saúde Coletiva. 2. ed. São Paulo: Hucitec; 2015. p. 719-38.

22. Cunha GT. A construção da clínica ampliada na Atenção Básica. [dissertação]. Campinas: Faculdade de Ciências Médicas, Universidade Estadual de Campinas; 2004.

23. Leavell H, Clark EG. Preventive medicine for the doctor in his community. New York: Macgraw Hill; 1965.

24. Carta de Ottawa. In: $1^{\text {a }}$ Conferência Internacional sobre Promoção da Saúde. Ottawa, Canadá; 1986 [acesso em 2018 dez 5]. Disponível em: http://bvsms.saude.gov.br/bvs/publicacoes/carta_ottawa.pdf.

25. Carvalho SR. Os múltiplos sentidos da categoria "empowerment” no projeto de Promoção à Saúde. Cad. Saúde Pública. 2004; 20(4):1088-1095.

26. Campos GWS, Barros RB, Castro AM. Avaliação de política nacional de promoção da saúde. Ciênc. Saúde Colet. 2004 [acesso em 2020 set 22]; 9(3):745749. Disponível em: https://www.scielo.br/scielo. php?pid=S1413-81232004000300025\&script $=$ sci $_{-}$ abstract\&tlng=pt. 
27. Almeida Filho N. Transdisciplinaridade e saúde. Ciênc. Saúde Colet. 1997; (1/2):5-20.

28. Peduzzi M. Equipe multiprofissional de saúde: a interface entre trabalho e interação. Campinas. [tese]. Campinas: Faculdade de Ciências Médicas, Universidade Estadual de Campinas; 1998. [acesso em 2020 set 22]. Disponível em: http://repositorio.unicamp. br/jspui/handle/REPOSIP/310392.

29. European Society of Cardiology; European Society of Hypertension. Guidelines for the Management of Arterial Hypertension. Eur Heart J 2018; 39(33):30213104.

30. Scala LC, Magalhães LB, Machado A. Epidemiologia da hipertensão arterial sistêmica. In: Moreira SM, Paola AV. Sociedade Brasileira de Cardiologia. Livro Texto da Sociedade Brasileira de Cardiologia. 2. ed. São Paulo: Manole; 2015. p. 780-5.

31. Campos GWS, Cunha GT, Figueiredo MD. Práxis e formação Paideia: apoio e cogestão em saúde. São Paulo, SP: Hucitec; 2013.

32. Freire P. Pedagogia do oprimido. 42.ed. Rio de Janeiro: Paz e Terra; 2005.

33. Cunha EM, Giovanella L. Longitudinalidade/continuidade do cuidado: identificando dimensões e variáveis para a avaliação da Atenção Primária no contexto do sistema público de saúde brasileiro. Ciênc. Saúde Colet. 2011; 16(supl1):1029-42.

34. Pereira Gray DJ, Sidaway-Lee K, White E, et al. Continuity of care with doctors - a matter of life and death? A systematic review of continuity of care and mortality. BMJ Open [internet]. 2018 [acesso em $2018 \mathrm{dez}$ 3]; 8(6):e021161. Disponível em: https://bmjopen. bmj.com/content/8/6/e021161.

35. Foucault M. O sujeito e o poder. In: Dreyfus H, Rabinow P. Michel Foucault uma trajetória filosófica. Rio de Janeiro: Forense Universitária; 1995. p. 231-249.
36. Foucault M. Microfísica do poder. Rio de Janeiro: Edições Graal; 1979.

37. Dahlgren G, Whitehead M. Policies and Strategies to Promote Social Equity in Health. Stockholm, Sweden: Institute for Futures Studies; 1991.

38. Malta DC, Bernal RTI, Souza MFM, et al. Social inequalities in the prevalence of self-reported chronic non-communicable diseases in Brazil: national health survey 2013. Int J Equity Health. 2016; (15):153.

39. Szwarcwald CL, Souza-Júnior PRB, Damacena GN, et al. Recomendações e práticas dos comportamentos saudáveis entre indivíduos com diagnóstico de hipertensão arterial e diabetes no Brasil: Pesquisa Nacional de Saúde (PNS), 2013. Rev Bras Epidemiol 2015; 18(supl2):132-45.

40. Lima MT, Bucher JSNF, Lima JWO. A hipertensão arterial sob o olhar de uma população carente: estudo exploratório a partir dos conhecimentos, atitudes e práticas. Cad. Saúde Pública 2004; (20):1079-87.

41. Leite SN, Vasconcellos MPC. Adesão à terapêutica medicamentosa: elementos para a discussão de conceitos e pressupostos adotados na literatura. Ciênc. Saúde Colet. 2003; (8):775-782.

42. Vaitsman J, Andrade GRB. Satisfação e responsividade: formas de medir a qualidade e a humanização da assistência à saúde. Ciênc. Saúde Colet. 2005; 10(3):599-613.

43. Freud S. Por que a guerra? (1933 [1932]). In: Edição standard brasileira das obras psicológicas completas de Sigmund Freud, v. XXII. Rio de Janeiro: Imago; 1976. p. 235-259.

Recebido em 29/11/2019

Aprovado em 11/08/2020

Conflito de interesses: inexistente

Suporte financeiro: não houve 